\title{
A comprehensive insight into the geography of forest cover in Italy: Exploring the importance of socioeconomic local contexts
}

\author{
Carlotta Ferrara ${ }^{a}$, Margherita Carlucci ${ }^{\text {b }}$, Efstathios Grigoriadis ${ }^{c}$, Piermaria Corona ${ }^{\text {, }}$, Luca Salvati ${ }^{\text {a,* }}$ \\ a Council for Agricultural Research and Economics (CREA-RPS), Via della Navicella 2, I-00184 Rome, Italy \\ ${ }^{\mathrm{b}}$ Department of Social and Economic Sciences (DISSE), University of Rome 'La Sapienza', Piazzale A. Moro 5, I-00185 Rome, Italy \\ c Department of Architecture and Project, Sapienza University of Rome, Via Flaminia 396, I-00196 Rome, Italy \\ d Council for Agricultural Research and Economics Forestry Research Centre (CREA-SEL), Viale Santa Margherita 80, I-52100 Arezzo, Italy
}

\section{A R T I C L E I N F O}

\section{Article history:}

Received 31 December 2015

Received in revised form 30 October 2016

Accepted 21 November 2016

Available online $\mathrm{xxxx}$

\section{Keywords:}

Forest land

Land-use change

Socioeconomic profile

Indicator

Southern Europe

\begin{abstract}
A B S T R A C T
Forest cover is a key attribute of local communities and affects the spatial organization of any given region. Changes in forest cover are influenced by spatially-varying biophysical and anthropogenic factors mainly associated with urban-rural, coastal-inland and elevation gradients. The present study investigates the relationship between the socioeconomic structure of local communities and selected indicators of forest landscape in Italy, including change in forest area over time (2000 - 2012), using an exploratory multivariate analysis based on principal component analysis, hierarchical clustering and discriminant analysis. We assess the importance of socio-spatial structures, economic dynamics and demographic patterns in the geography of forest cover, expansion and loss, considering 149 statistical indicators that are used to evaluate the multiple dimensions of sustainable development. The results point to agriculture, income, education and labour market indicators as a key predictors of contexts with high forest cover and moderate changes in forest area (both gain and loss) from those with low forest cover and marked changes in forest area. High forest cover in rural districts was spatially associated with local communities featuring depopulation, unemployment, low educational levels and subsistence agriculture. These factors consolidate land abandonment and soil erosion. The highest rate of change in forest area was observed in economically-growing, accessible local contexts with dynamic socio-demographic profiles. Integrated environmental and socioeconomic policies for sustainable development are required to incorporate forest cover and changes in wooded area as pivotal variables and may benefit from a better understanding of the role of local communities in forest management.
\end{abstract}

(c) 2016 Published by Elsevier B.V.

\section{Introduction}

Ecological disturbance caused by human-driven landscape transformations is the main cause of biodiversity loss, habitat fragmentation and land degradation (Foley et al., 2005; Baptista and Rudel, 2006; Blondel et al., 2010). Therefore, assessing landscape characteristics and environmental quality plays a crucial role in natural resource planning and biodiversity conservation (Sirami et al., 2010; Salvati et al., 2013a, b). High-quality natural environments (e.g. forests, shrubland, pastures, wetlands) require renewed monitoring approaches based on their joint socioeconomic and landscape value (Marchetti et al., 2014). Approaches that concentrate on the role of local socioeconomic contexts are particularly needed to ascertain the dynamic patterns underlying complex socio-ecological systems (Safriel and Adeel, 2008; Raymond et al., 2009), especially those exposed to processes of environmental degradation driven by climate and land-use changes, desertification, soil and water pollution (Hill et al., 2008; Salvati and Zitti, 2009; Imeson,

\footnotetext{
* Corresponding author.

E-mail address: luca.salvati@crea.gov.it (L. Salvati).
}

2012). Local communities reflect the long-term interplay between man and natural resources as a result of joint demographic, cultural, political and economic processes (Salvati and Carlucci, 2011), in turn promoting feedbacks, influencing thresholds and determining synergies in complex socio-environmental systems (Kelly et al., 2015).

The characteristics of local communities are important factors shaping forest landscape, from the stand level to forest compartment and landscape level (e.g. Konijnendijk et al., 2006; Zhang et al., 2010). Understanding the human-forest relationship requires consideration of the "economic behaviour in relation to social structures and processes as well as a necessary focus on the context-bounded and culturally rooted human actors' behaviour" (Schlüter and von Detten, 2011, p. 326). Regional disparities, economic marginality, rural poverty and increased anthropogenic pressure on ecologically-fragile land have been hypothesized to be decisive in the depletion of the forest resource base in both affluent and emerging countries (Blaikie and Brookfield, 1987; Boardman et al., 2003; Iosifides and Politidis, 2005). However, although an essential component in the analysis of drivers of change, the spatial distribution of forest cover and the socio-economic profile of local communities has been little studied. One exception is the work reported by 